\title{
Number of Severe Episodes
}

National Cancer Institute

\section{Source}

National Cancer Institute. Number of Severe Episodes. NCI Thesaurus. Code C124330.

The number of times an event, which is classified as severe, occurred. 